\title{
Abrasive wear behaviour of aluminium hybrid nanocomposites produced by ultrasonication assisted casting method
}

\author{
Poovazhagan Lakshmanan \\ S.S.N College of Engineering, Kalavakkam, \\ Chennai - 603110, Tamilnadu, India \\ Email; poovazhaganl@ssn.edu.in \\ Phone: +91 442498 6474; Fax: +91 4424982656
}

\begin{abstract}
In this investigation, the abrasive wear resistance of $\mathrm{Al} /\left(\mathrm{B}_{4} \mathrm{C}+\mathrm{SiC}\right)$ hybrid nanocomposites was tested against hard $\mathrm{SiC}$ abrasive sheets and compared to those of unreinforced $\mathrm{Al}$ alloy. Three loadings of nano-SiC $(0.5,1.0$, and $1.5 \mathrm{Wt}$. \%) and one loading of nano- $\mathrm{B}_{4} \mathrm{C}(0.5 \mathrm{Wt}$. \%) were mixed with an aluminium alloy to produce the aluminium hybrid nanocomposites using an ultrasonication assisted casting method. Scanning electron microscopy showed a uniform distribution of nanoparticles in the Al alloy. Transmission electron microscopy indicated an increase in the dislocation density of nanocomposites compared to monolithic Al. The abrasive wear experiments were conducted on a Pin-on-Disc tribometer using pins of $9 \mathrm{~mm}$ diameter and $15 \mathrm{~mm}$ height under dry sliding conditions at room temperature. The wear rate in terms of wear volume per unit weight was calculated for both unreinforced alloy and hybrid nanocomposites. It was observed that $\mathrm{Al}$ hybrid nanocomposites showed superior wear resistance properties compared to the unreinforced sample. The nanocomposite with $1.5 \mathrm{Wt} . \%$ nano-SiC and $0.5 \mathrm{Wt} \%$ nano- $\mathrm{B}_{4} \mathrm{C}$ possessed better wear resistance properties compared to the other composites tested in this work. The worn out surface of the Al alloy and its hybrid nanocomposites imply that the wear mechanism is through plowing action on the surface by $\mathrm{SiC}$ abrading particulates. The nanocomposite with $1.5 \mathrm{Wt} \% \mathrm{SiC}$ and $0.5 \mathrm{Wt} . \% \mathrm{~B}_{4} \mathrm{C}$ showed $88.32 \%$ increase in wear resistance compared to the monolithic Al. This combination of material can be selected for abrasive wear resistance applications.
\end{abstract}

Keywords: Abrasive wear; friction coefficient; hybrid nanocomposites; transmission electron microscopy; microhardness

\section{INTRODUCTION}

The possibility of producing metal matrix composites (MMCs) with tailor-made properties has led to their applications in different fields of engineering including automobile, aircraft, marine, and sports industries [1-5]. The MMCs containing particulate reinforcements have homogenous properties which are attractive to design engineers due to their easy adaptability to current design practices. The near-net-shape production of MMCs using conventional methods makes these materials more striking even from the point of view of manufacturing components. However, the high cost associated with the presently available MMCs remains a major barrier to their widespread use. Aluminium alloys reinforced with micro-ceramic particulates generally referred as Al-metal matrix composites (Al-MMCs) are gaining widespread attractiveness in several 
engineering fields due to their better mechanical and wear resistance properties compared to their unreinforced counterparts [6-9]. Nowadays, Al-MMCs are being used as base materials in several applications such as pistons, pushrods, cylinder liners, and brake discs. Particulate reinforced Al-MMCs have gained broad applications in automotive and aerospace industries due to their enhanced properties [10-12]. These include low density, high specific strength and stiffness, good fatigue properties, dimensional stability at high temperatures, and adequate tribological properties $[11,13]$. The wear properties of TiC particulates reinforced Al-matrix composites were analysed by Ramakoteswararao et al. [14]. The use of metal matrix composites for automotive applications was studied by Fatchurrohman et al. [15]. The attractive features of metal matrix composites have influenced their use in automobile brake pad applications [16]. The erosive wear behaviour of $\mathrm{SiC}$ particulates reinforced with Al-metal matrix composites was systematically analysed by Khan and Dixit [17]. However, the above works have mainly focused on the effect of micron-sized particulates on metal matrices. With the reduction of the ceramic particulates' size from micro to nano, the mechanical and wear resistance properties of MMCs can be further improved.

The use of nanocomposites is gaining importance in the last two decades [18]. Due to its excellent resistance to abrasion and low density, boron carbide $\left(\mathrm{B}_{4} \mathrm{C}\right)$ can be used as a reinforcing material with many matrix materials. However, its high cost has prevented its widespread use. Silicon carbide $(\mathrm{SiC})$ being a cheaper reinforcement compared to $\mathrm{B}_{4} \mathrm{C}$ is instead used in most of the applications. In this work, an attempt has been made to utilise $\mathrm{B}_{4} \mathrm{C}$ and $\mathrm{SiC}$ at optimum levels in $\mathrm{Al}$ to increase its abrasive wear resistance properties.

The uniform mixing of nanoparticles is a major obstacle in nanocomposite manufacturing. One method which guarantees the uniform mixing of nanoparticles in the metal melt is the ultrasonic cavitation-assisted casting process. In this method, a high intensity of cyclic sound waves is introduced in the metal melt, which in turn induces the cavitation effect. The formation and collapse of these cavitation bubbles develop a huge amount of energy which helps to uniformly distribute the nanoparticles in the metal melt $[18,19]$. The abrasive wear behaviour of Al-composites has been studied by various authors. Most of the works used conventional fabrication methods like stir casting or powder metallurgy for the manufacturing of the composites. Generally, reinforcement powders used in these works are of micrometer size [20-24]. Only very few works reported in the area of abrasive wear studies have used Al hybrid composites. By considering the above factors, in this work, we made an attempt to fabricate and study the abrasive wear behaviour of $\mathrm{Al}$ hybrid nanocomposites reinforced with the optimum weight percentage of nano- $\mathrm{B}_{4} \mathrm{C}$ and nano-SiC using a novel ultra-sonication assisted casting method.

\section{MATERIALS AND METHODS}

\section{Materials Used}

The materials used in this work were $6061 \mathrm{Al}$ alloy nanocomposites reinforced with three different Wt. \% of $\mathrm{SiC}(0.5,1.0$ and 1.5$)$ and a constant Wt. \% of $\mathrm{B}_{4} \mathrm{C}(0.5 \%)$. Properties of the matrix and reinforcement are provided in Table 1 . They were fabricated via an ultrasonic assisted casting process with an average particle size of $50 \mathrm{~nm}$. Table 2 shows the various materials tested in this study. The materials were chosen such that their densities were closer; hence, segregation or floating of particles in the melt is not a major issue during the casting process. Considering cost-effectiveness, the weight fraction of 
$\mathrm{B}_{4} \mathrm{C}$ was maintained constant. The average size of both $\mathrm{SiC}$ and $\mathrm{B}_{4} \mathrm{C}$ nanoparticles is around $50 \mathrm{~nm}$. Due to the large surface area of nanoparticles, even a very small amount of nanoparticles can have a huge impact on the mechanical properties of the composites.

Table 1. Properties of matrix and reinforcement.

\begin{tabular}{llllll}
\hline Material & $\begin{array}{c}\text { Density } \\
\left(\mathrm{g} / \mathrm{cm}^{3}\right)\end{array}$ & $\begin{array}{c}\text { Melting } \\
\text { Point }\left({ }^{\circ} \mathrm{C}\right)\end{array}$ & $\begin{array}{c}\text { Modulus of } \\
\text { Elasticity } \\
(\mathrm{GPa})\end{array}$ & $\begin{array}{c}\text { Thermal } \\
\text { Conductivity } \\
(\mathrm{W} / \mathrm{m}-\mathrm{K})\end{array}$ & $\begin{array}{c}\text { Coefficient of } \\
\text { thermal expansion } \\
\left(\mathrm{m} / \mathrm{m}^{0} \mathrm{C}\right)\end{array}$ \\
\hline AA6061 & 2.71 & 620 & 70 & 180 & $23 \times 10^{-6}$ \\
$\mathrm{SiC}$ & 3.20 & 2700 & 420 & 120 & $4 \times 10^{-6}$ \\
\hline
\end{tabular}

Table 2. Materials tested.

\begin{tabular}{lcc}
\hline \multicolumn{1}{c}{ Material } & Weight fraction of SiC & Weight fraction of $\mathrm{B}_{4} \mathrm{C}$ \\
\hline Monolithic Al & 0 & 0 \\
Al 99.0-0.5-0.5 & 0.5 & 0.5 \\
Al 98.5-1.0-0.5 & 1.0 & 0.5 \\
Al 98.0-1.5-0.5 & 1.5 & 0.5 \\
\hline
\end{tabular}

\section{Synthesis of Hybrid Nanocomposites}

The hybrid nanocomposites were synthesised using an ultrasonication assisted casting setup which is shown in Figure 1. The setup consists of an Al melting furnace, an electrical motor and stirrer, an ultrasonic generator, and an argon gas supply unit. An indigenously fabricated $65 \mathrm{~mm}$ diameter and $165 \mathrm{~mm}$ length stainless steel (SS) 310grade crucible was used for melting and processing the hybrid nanocomposites. The gateway and handle provided for the crucible facilitate the easy pouring of the molten material into the preheated die.

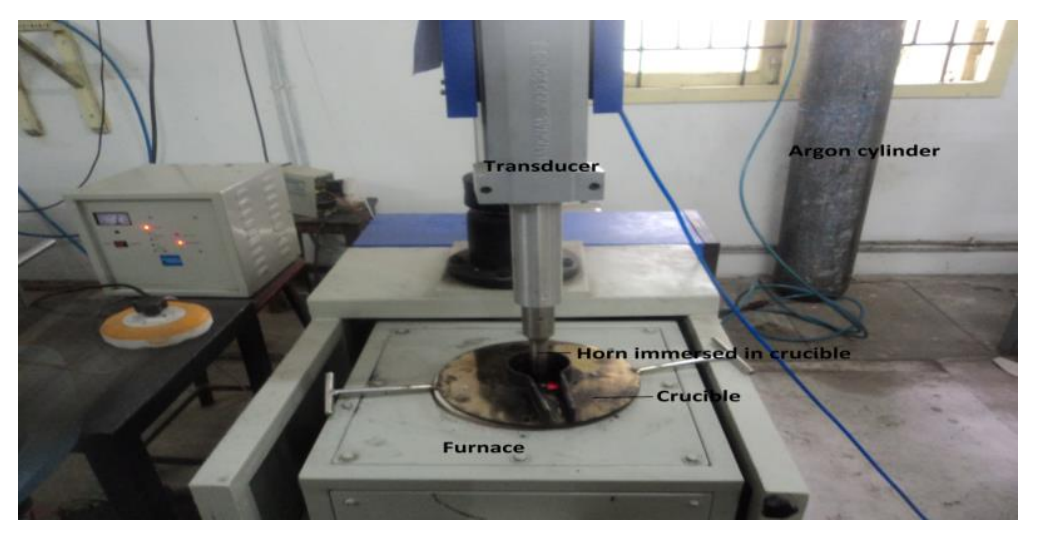

Figure 1. Ultrasonication assisted casting setup.

The flow chart of the experimental procedures for manufacturing hybrid nanocomposites is presented in Figure 2 as a flow chart. The required amount of $\mathrm{Al}$ alloy was weighed and melted in the furnace at $700{ }^{\circ} \mathrm{C}$. The alloy melt was choked at this temperature for about 10 minutes. Subsequently, the melt was mechanically stirred for two minutes to obtain a homogeneous mixture of alloy and then, the mixture of $\mathrm{SiC}$ and $\mathrm{B}_{4} \mathrm{C}$ nanoparticulates was slowly added into the molten material from the top of the 
crucible. Mechanical stirring was continued for 15 minutes to pre-mix the nanoparticulates and also reduce the sonication (ultrasonic processing) time.

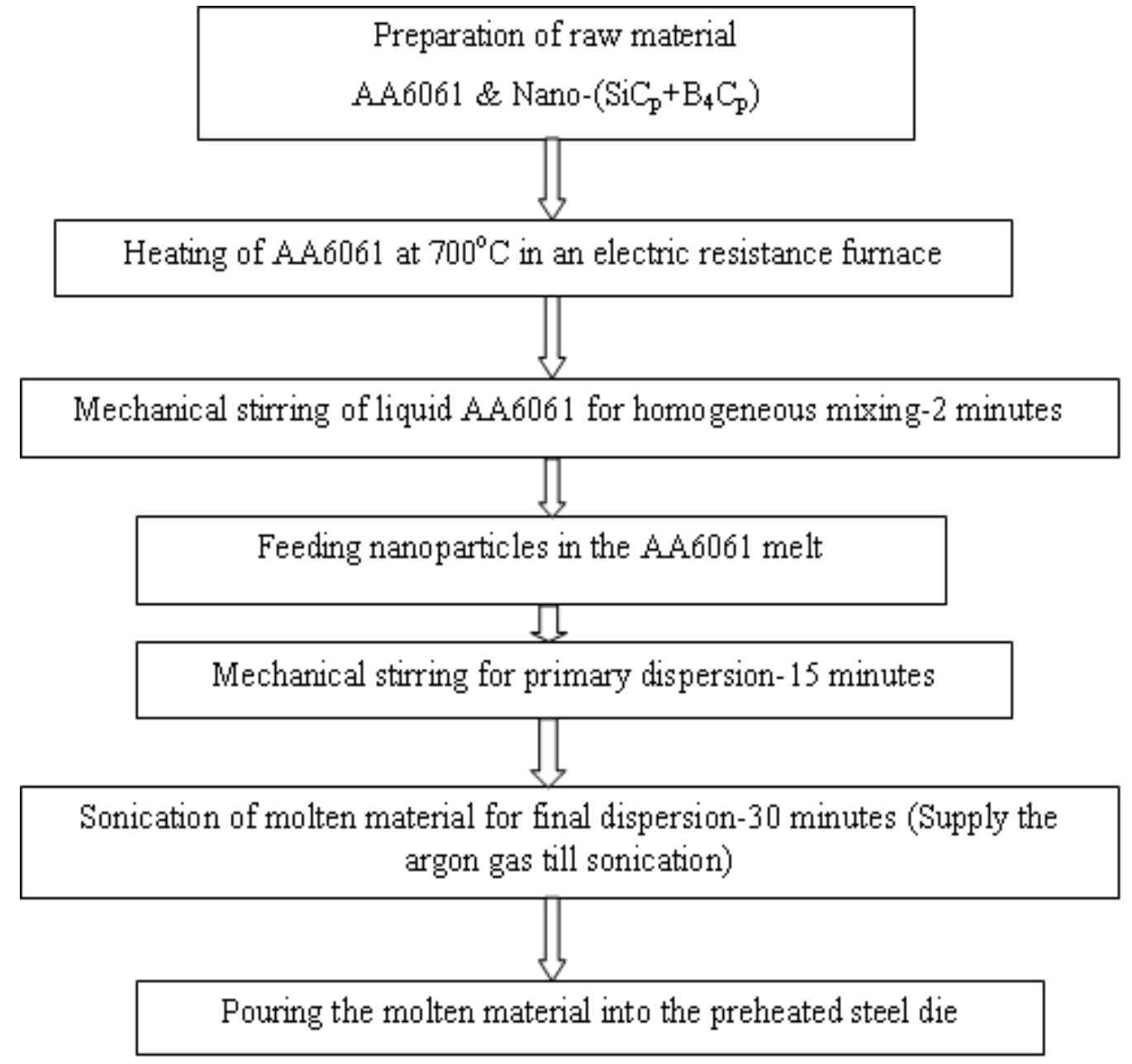

Figure 2. Procedures for manufacturing hybrid nanocomposites by ultrasonication assisted casting process.

At the end of mechanical stirring, the stirrer was removed and a Ti horn was dipped in the molten material at $30 \mathrm{~mm}$ [19] and the ultrasonic wave generator was switched on. The melt was sonicated for about 30 minutes for all the experiments. During sonication, when the intensity of the ultrasonic waves was greater than that of the liquid Al bonding energy, it broke the liquid Al bonds and developed cavitation bubbles inside the molten material. The implosion of these cavitation bubbles during a high-pressure cycle ensures the breaking of clustered particulates in all directions randomly. Hence, the agglomeration tendencies of nanoparticulates were abridged enormously after efficient ultrasonic processing. The intermittent vibrating mode with pulse ON-OFF time fixed at $1 \mathrm{~s}$ and 0.5 $\mathrm{s}$ was used for melt processing. The supply of argon gas during processing reduces the reaction between the atmospheric gas and the molten material. During sonication, the viscosity of the melt significantly increases due to the addition of nanoparticulates. Thus, after efficient sonication, a higher casting temperature of $800{ }^{\circ} \mathrm{C}$ was used to ensure better flowability of the melt into the preheated steel die. 


\section{Abrasive Wear Tests}

Abrasive wear tests were performed on a MAGNUM/POD pin-on-disc tribometer (Figure 3a). A schematic representation of the abrasive wear experiments is shown in Figure 3 (b). SiC abrasive sheets of grade 1000 were pasted on the disc of the pin-on-disc machine. All the abrasive wear tests were conducted at room temperature and at dry sliding conditions. Five pins of diameter $9 \mathrm{~mm}$ and length $15 \mathrm{~mm}$ were machined from each weight percentage of hybrid reinforcements. Abrasive tests were carried out by changing the normal load, sliding speed and sliding distance.
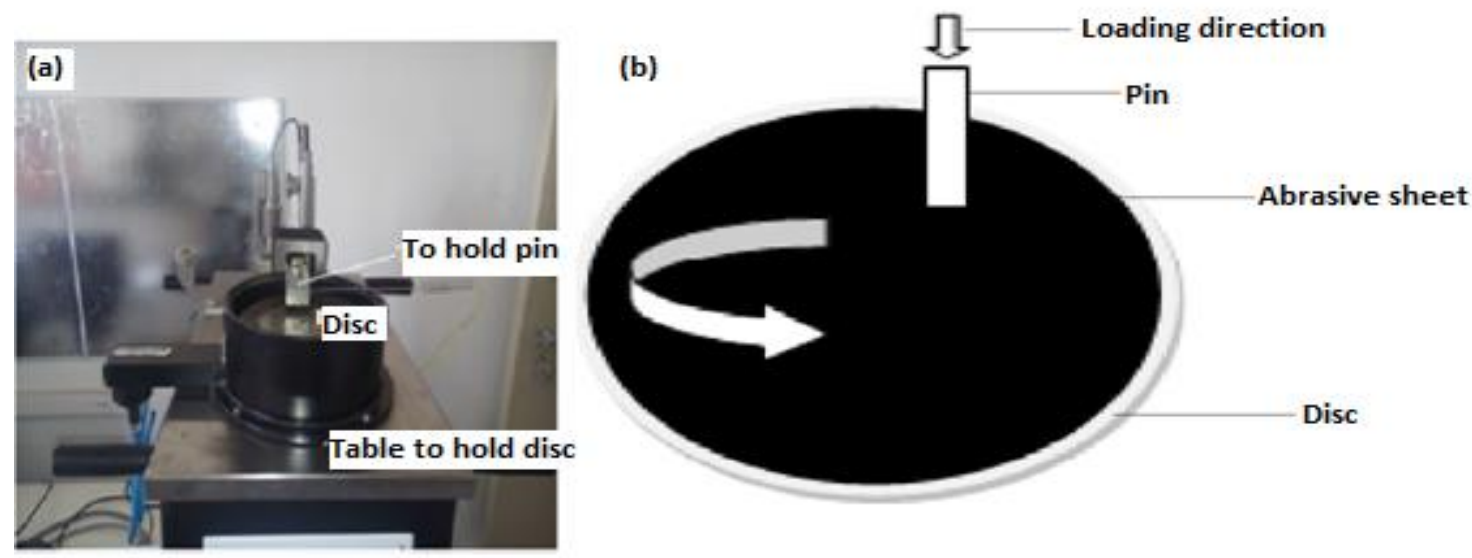

Figure 3. (a) Pin-on-disc tribometer (b) Schematic representation of abrasive wear test.

Test specimens were abraded against the normal load of 10, 20, and $30 \mathrm{~N}$. The other test parameters were: rotating speed $500 \mathrm{rpm}$ and track radius $50 \mathrm{~mm}$. To ascertain the same contact area, the surface of the specimens were ground with 800 -grade abrasive paper. Acetone was used to clean the surface of the specimens. An electronic weighing machine with an accuracy of $0.1 \mathrm{mg}$ was used to weigh the specimens before and after each test.

\section{RESULTS AND DISCUSSION}

\section{Microstructure}

Figure 4 shows the scanning electron microscopy (SEM) image of the $\mathrm{Al} /\left(0.5 \mathrm{~B}{ }_{4} \mathrm{C}+0.5\right.$ $\mathrm{SiC})$ nanocomposite sample. It was noted that the ceramic nanoparticles were uniformly distributed in the Al matrix. Numerous amounts of individual nanoparticles were observed in the Al matrix which was due to the effect created by the high-intensity ultrasonic cavitation process. It was also understood that at this magnification (40X), it is very difficult to distinguish the ceramic particles ( $\mathrm{SiC}$ or $\mathrm{B}_{4} \mathrm{C}$ ) in the SEM images. Uniformly distributed nanoparticles are the prime reason for the enhanced mechanical properties of the material.

The major strengthening mechanism in the particle reinforced composite materials is its increased dislocation density [25]. To evaluate the increase in dislocation density of the nanocomposite, transmission electron microscopy (TEM) images were taken of the monolithic $\mathrm{Al}$ and $\mathrm{Al} /\left(0.5 \mathrm{~B}_{4} \mathrm{C}+0.5 \mathrm{SiC}\right)$ nanocomposite. 


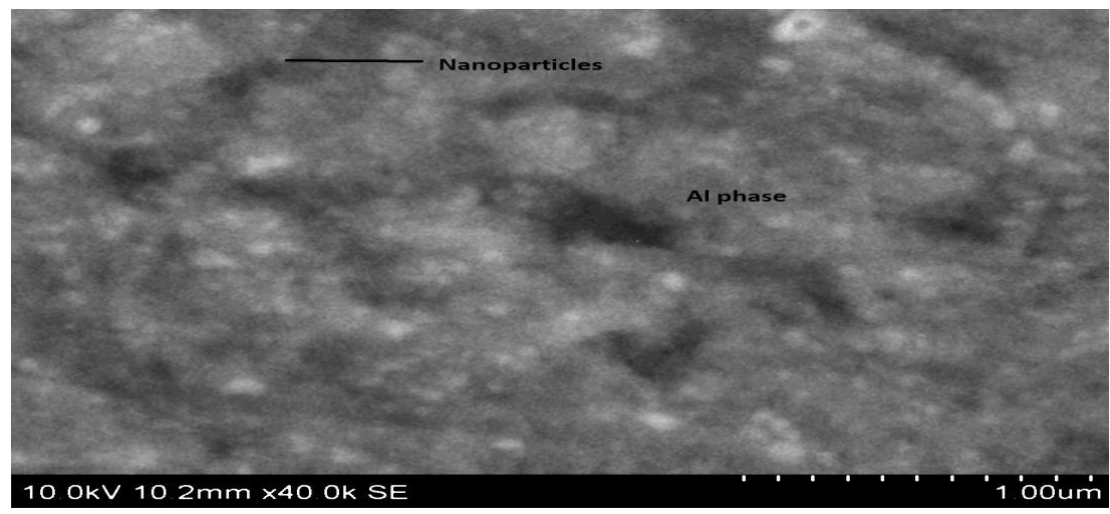

Figure 4. SEM image of a nanocomposite.

Figure 5(a) represents the TEM image of monolithic Al. Very few dislocations were observed in the image. Figure 5(b) shows the TEM image of the nanocomposite sample. Compared to the monolithic Al, a very large amount of dislocations was observed in the nanocomposite sample. The increase in dislocation density in nanocomposite is explained in the following manner. The large difference in the coefficient of thermal expansion and elastic modulus mismatch between Al matrix and ceramic nanoparticles generates a huge amount of geometrically necessary dislocations on the nanocomposite samples $[25,26]$. In the case of monolithic $\mathrm{Al}$, the same concept is not applicable.
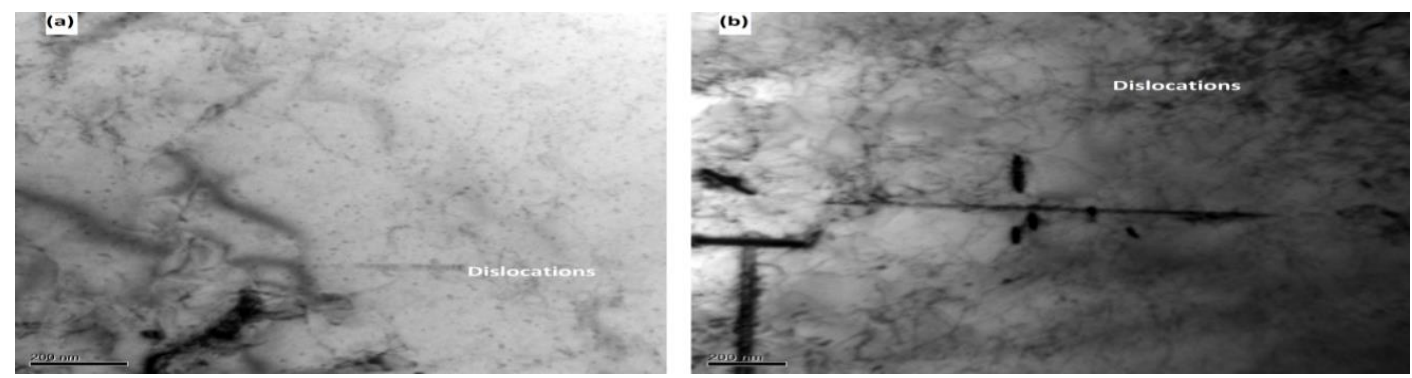

Figure 5. TEM Image of (a) Monolithic Al (b) Nanocomposite

\section{Microhardness}

Microhardness tests were carried out on metallographically polished samples of monolithic $\mathrm{Al}$ and hybrid nanocomposites by applying $0.5 \mathrm{kgf}$ of the load for a dwell period of 10 seconds using a Vickers microhardness tester. The tests were performed at three different locations of the specimens in order to contradict the probability of the indenter resting on hard ceramic particles. Microhardness was calculated based on the average of the three readings. The variation of microhardness with $\mathrm{Wt} . \%$ of hybrid reinforcement is presented in Figure 6. For comparison, the microhardness of the monolithic $\mathrm{Al}$ was also included. It was observed that there was a significant increase in the microhardness values with the reinforcement content. A maximum hardness improvement of about $67 \%$ was observed in the $\mathrm{Al} /\left(0.5 \mathrm{~B}_{4} \mathrm{C}+1.5 \mathrm{SiC}\right)$ nanocomposite compared to the unreinforced $\mathrm{Al}$-alloy. Hard $\mathrm{SiC}$ and $\mathrm{B}_{4} \mathrm{C}$ particles provide the intrinsic property of hardness to the matrix material, thereby enhance its resistance to deformation. Due to the large thermal expansion and elastic modulus mismatch between the ceramic particles and $\mathrm{Al}$ alloy, an enormous amount of geometrically necessary dislocations were generated during solidification at the particle-matrix interface area[25]. The increase in 
dislocation at the interfaces increases the hardness of the materials as the dislocations entangled with each other and thus, reduced plastic deformation [25]. Another factor that contributes to the increase in hardness of the nanocomposite was the large surface to volume ratio of nanoparticles. The large surface area of nano-sized reinforcements increased the particle-matrix interface area, which in turn increased the hardness of the nanocomposites [27].

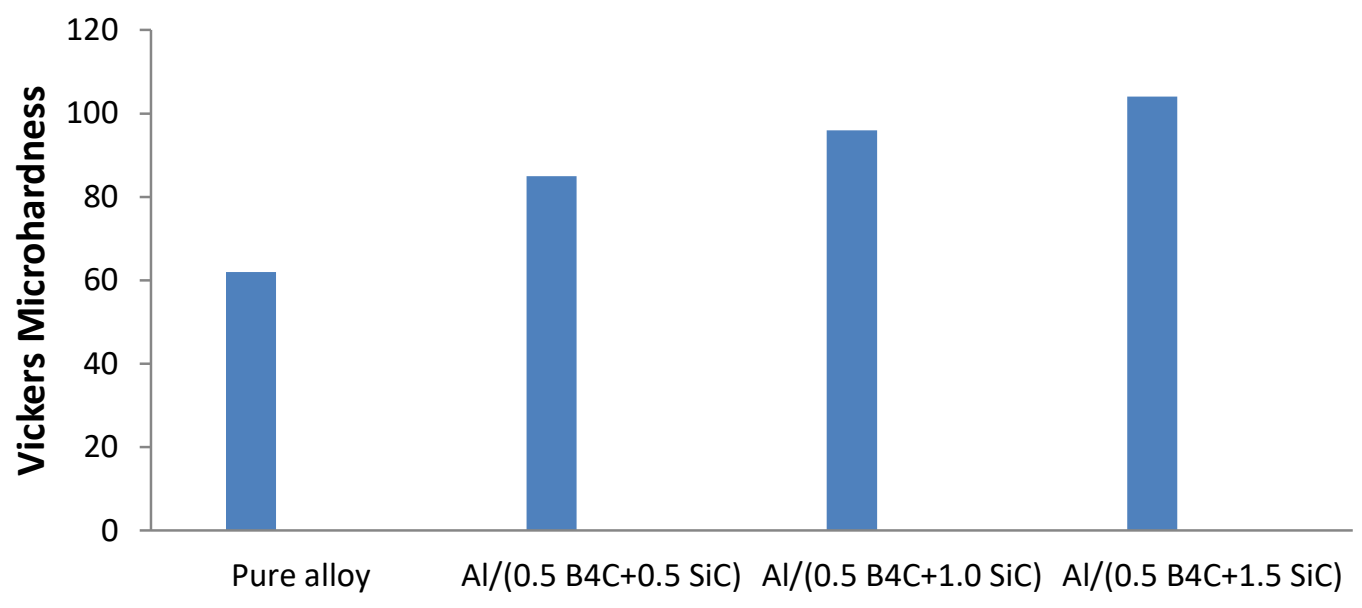

Figure 6. Microhardness Vs Wt.\% of hybrid reinforcement.

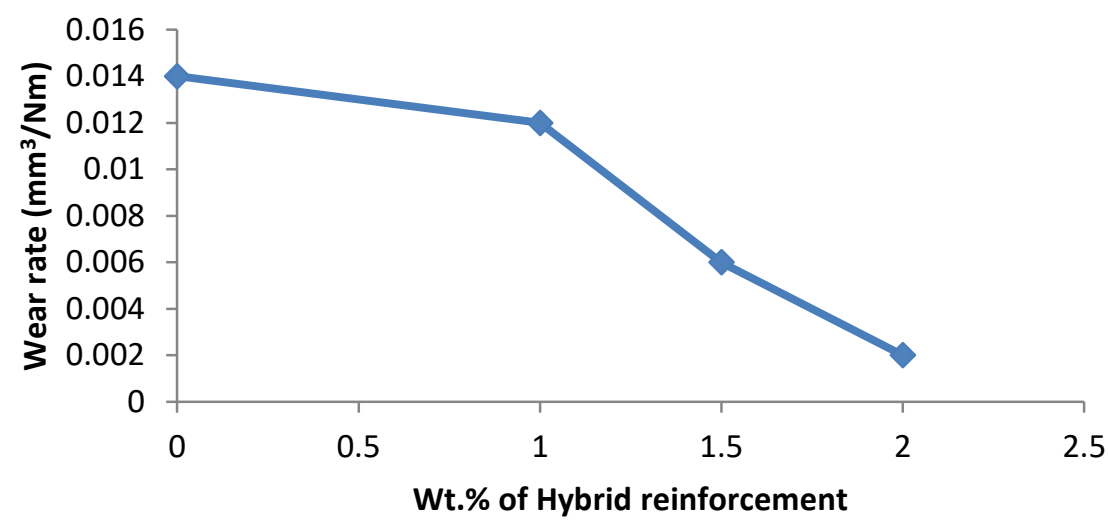

Figure 7. Wear rate Vs Wt.\% of reinforcement

\section{Wear Rate Vs Wt.\% of Reinforcement}

Figure 7 shows the variation of wear rate of monolithic $\mathrm{Al}$ and hybrid nanocomposites as a function of Wt.\% of reinforcement at a constant load of $10 \mathrm{~N}$. It was clear that an increase in $\mathrm{Wt} . \%$ of reinforcement decreased the wear rate. The nanocomposite reinforced with $0.5 \mathrm{Wt} . \% \mathrm{SiC}$ and $1.5 \mathrm{Wt} . \% \mathrm{~B}_{4} \mathrm{C}$ yielded a minimum wear rate between all of the materials tested in this study. For this material, the increase in wear resistance was about $88 \%$ compared to the monolithic Al. This huge amount of increase in wear resistance in nanocomposite is attributed to the inclusion of hard ceramic nanoparticulates $\left(\mathrm{SiC}+\mathrm{B}_{4} \mathrm{C}\right)$ which act as the strengthening element. Similar results were previously reported by S. Kumar et al. 2010 and Sanjeev Das et al. 2007 [28, 29]. It was also concluded that the addition of nanoparticulates and the ultrasonication processing of nanocomposites had 
resulted in the combined effect of dispersion hardening and grain refinement, leading to an improvement in the wear resistance of $\mathrm{Al}$ alloy.

\section{Wear Rate Vs Normal load}

The wear rate vs. normal load graph is presented in Figure 8 at a constant rotating speed of $500 \mathrm{rpm}$. It can be observed that both $\mathrm{Al}$ alloy and $\mathrm{Al}$-nanocomposites' wear volume increases with the applied load. The rate of increase of wear volume gradually reduced as the reinforcement content increased. For the same loading conditions, the nanocomposite reinforced with $0.5 \mathrm{Wt} . \% \mathrm{~B}_{4} \mathrm{C}$ and $1.5 \mathrm{Wt} . \% \mathrm{SiC}$ showed the most minimum wear rate. It is well known that smaller sized particles blunt the $\mathrm{SiC}$ abrading particles in the abrasive sheet more effectively than larger sized particles. Size reduction of particles actually helps increase their sharpness $[30,31]$. The sharp-edged nano-sized ceramic particles help to blunt the abrading silicon carbide particles in the abrasive sheet. Even though the load is increased, the sharp-edged ceramic particles actually assist in reducing the rate of wear.

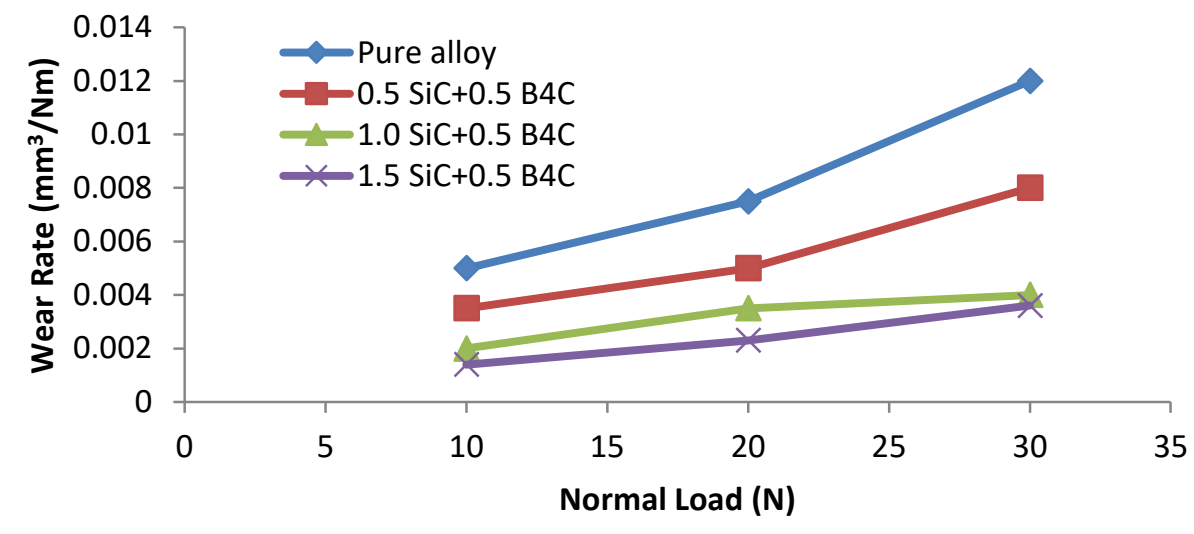

Figure 8. Wear rate against normal load.

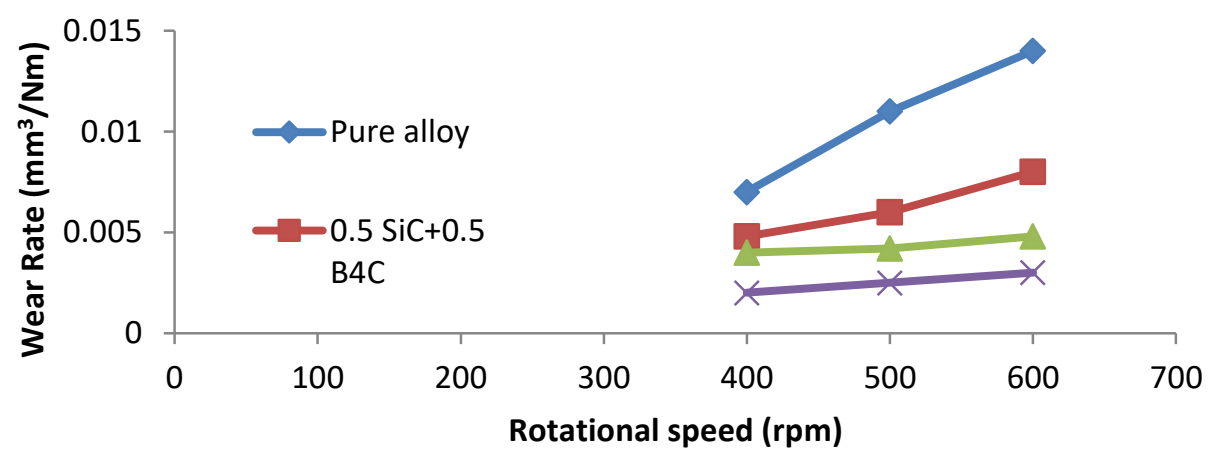

Figure 9 Wear rate against rotational speed.

\section{Wear rate Vs Speed}

The effect of disk rotating speed (rpm) on the wear rate is shown in Figure 9. The wear rates for the monolithic $\mathrm{Al}$ and its hybrid nanocomposites are plotted against rotating speed in Figure 9. It is immediately apparent that wear rates were higher at higher rotating speeds. Also, the wear rate was steeper for monolithic Al than that of the nanocomposites. Increasing the rotational speed from $400 \mathrm{rpm}$ to $600 \mathrm{rpm}$ increases heat generation in the nugget region, which leads to more softening of the Al matrix due to over aging. The high 
heat generation induced the matrix softening, which resulted in increased wear rate at higher speeds [23, 32].

\section{Friction Coefficient Vs Wt.\% Reinforcement}

Figure 10 shows the variation of friction coefficient for the nanocomposites and pure alloy. It should be noted that the friction coefficient of the pure $\mathrm{Al}$ and nanocomposite are in the expected range (0.36 to 0.40$)$ for light metals in dry sliding conditions [S. Das2001]. The friction coefficients of nanocomposites were lower than those of pure Al alloys while sliding under similar conditions. It was shown that in these tests, sample pins of $\mathrm{Al}$ alloys deformed plastically, which resulted in high friction coefficient. The lower coefficients of friction in the case of nanocomposites containing hard $\mathrm{SiC}$ and $\mathrm{B}_{4} \mathrm{C}$ nanoparticulates were due to the formation of tribofilm at the interface between pin and disk [31]

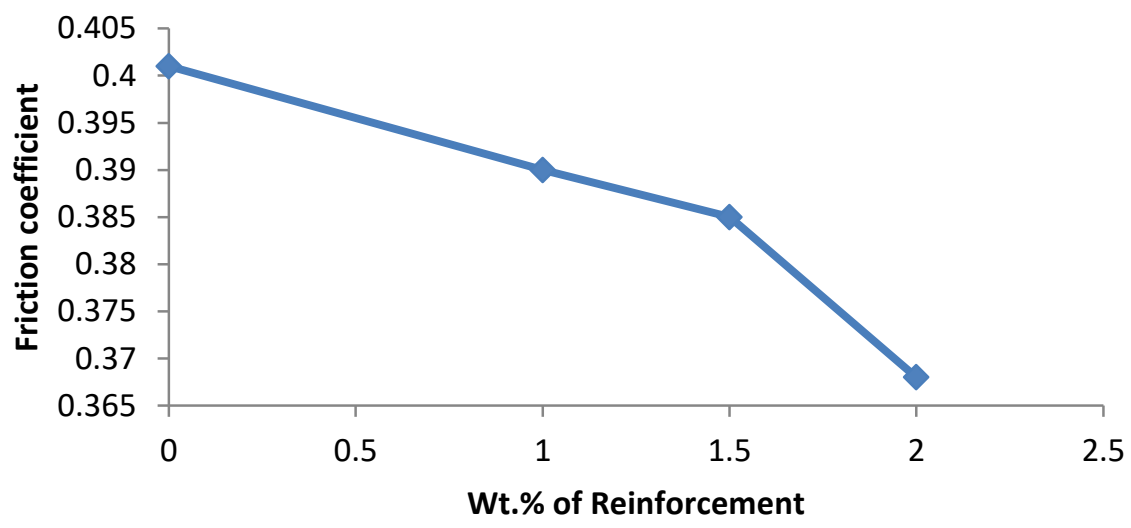

Figure 10. Friction coefficient Vs Wt.\% of reinforcement

\section{Friction Coefficient Vs Normal load}

The influence of normal load on the average value of the frictional coefficient for the unreinforced alloy and nanocomposites is presented in Figure 11. The test conditions were sliding velocity of $1.3089 \mathrm{~m} / \mathrm{s}$ and sliding distance of $500 \mathrm{~m}$. The graph shows that an increase in normal load gradually decrease the average frictional coefficient. Higher friction coefficient at lower normal loads is attributed to the following factors; less initial contact of asperities resulted in abrasive action and hence, high frictional coefficient [28]. An increase in the normal load led to good conformity of contact surfaces which reduced the plowing action and friction coefficient.

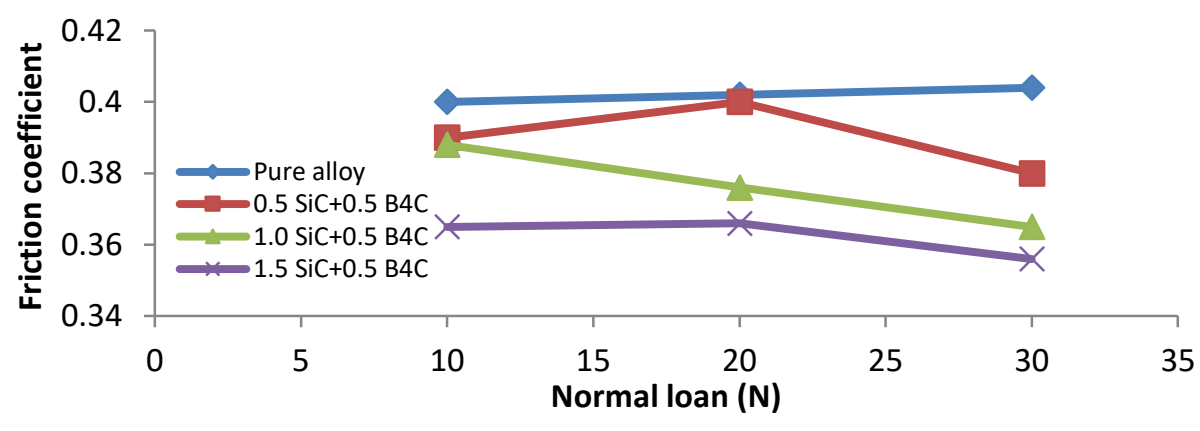

Figure 11. Friction coefficient against normal load. 


\section{Worn Surfaces-Scanning Electron Microscopic Images}

In order to understand the type of wear and wear mechanism, field emission scanning electron microscopic (FESEM) images were taken of the monolithic $\mathrm{Al}$ and its nanocomposites. Figure 12 (a) shows the FESEM micrographs of the worn surface of Al alloy at a normal load of $10 \mathrm{~N}$ and at a magnification of $200 \mathrm{X}$. The arrow mark indicates the sliding direction. The worn surface of $\mathrm{Al}$ alloy exhibited deep long grooves along the direction of sliding. High magnification of the FESEM image (Figure 12-b) confirmed the evidence of predominance of the ploughing mechanism in $\mathrm{Al}$ alloy. Ploughing is a process of displacing material from groove to sideways to form ridges adjacent to the grove produced and thus, repeated sliding of hard asperity leads to metal loss. A similar trend was observed in previous work by Kumar. S et al. 2008 [28].
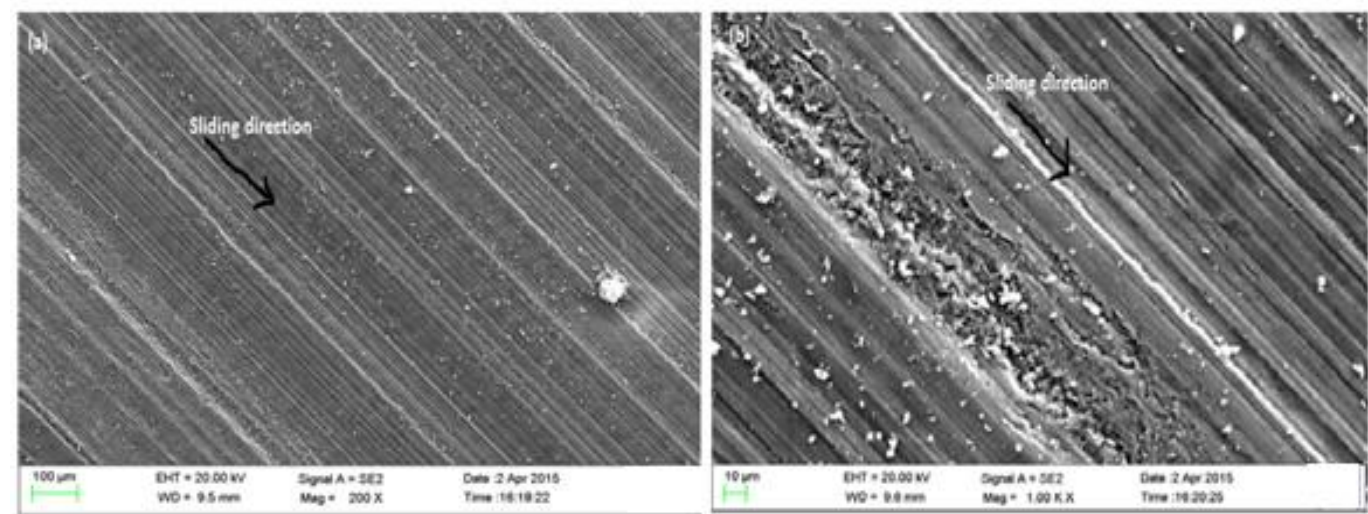

Figure 12. Worn surface FESEM images of Al alloy (a) at $10 \mathrm{~N}, 200 \mathrm{X}$ magnification (b) at $10 \mathrm{~N}, 1000 \mathrm{X}$ magnification.

The worn surface (Figure 13) of $\mathrm{Al} /\left(\begin{array}{lllll}0.5 & \mathrm{Wt} \% & \mathrm{~B} 4 \mathrm{C}+1.5 & \mathrm{Wt} \% & \mathrm{SiC}\end{array}\right)$ nanocomposite revealed narrow groves and an almost flat surface. This was due to the presence of hard $\mathrm{SiC}$ and $\mathrm{B}_{4} \mathrm{C}$ nanoparticulates which restricted the flow of material under the applied load. In addition, the worn surface of the nanocomposites has higher hardness and hence the ploughing tendency of the hard asperity of the counter face was less compared to the soft matrix alloy $[12,33,34]$.
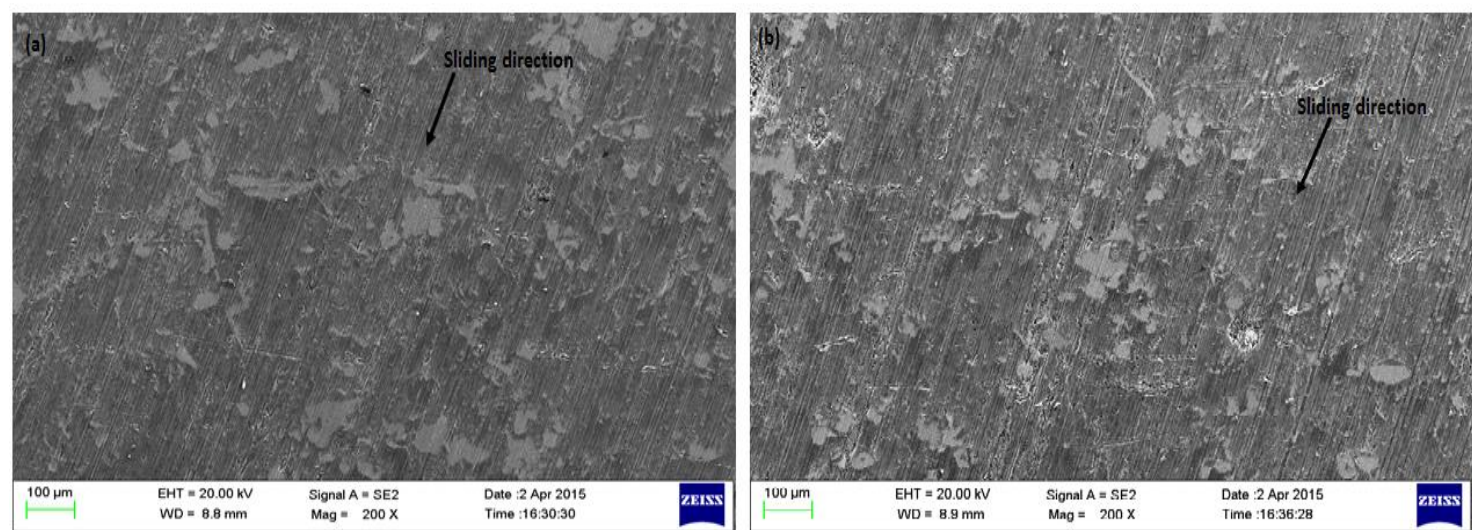

Figure 13. Worn surface FESEM images of $\mathrm{Al} /(0.5 \mathrm{Wt} . \% \mathrm{~B} 4 \mathrm{C}+1.5 \mathrm{Wt} . \% \mathrm{SiC})$ nanocomposite (a) at $10 \mathrm{~N}$ (b) at $30 \mathrm{~N}$. 


\section{CONCLUSIONS}

Monolithic Al and its hybrid Al-nanocomposites were successfully synthesised by ultrasonication assisted casting process. Monolithic Al and hybrid Al-nanocomposites were tested for abrasive wear resistant properties against hard $\mathrm{SiC}$ abrasive sheets and the following conclusions arrived. SEM images confirmed the uniform dispersion of hybrid nanoparticles in $\mathrm{Al}$ matrix. TEM pictures evaluated the increased dislocation density in nanocomposites compared to the monolithic Al. Vickers microhardness tests revealed that the hardness of nanocomposites increased as the hybrid reinforcement content increased and the maximum hardness improvement of about $67 \%$ was observed in the $\mathrm{Al} /(0.5$ $\mathrm{B}_{4} \mathrm{C}+1.5 \mathrm{SiC}$ ) nanocomposite sample.

Abrasive wear resistance of $6061 \mathrm{Al}$ alloy significantly increased by the addition of hard $\mathrm{SiC}$ and $\mathrm{B}_{4} \mathrm{C}$ nanoparticulates. Nanocomposite with $0.5 \mathrm{Wt} . \% \mathrm{~B}_{4} \mathrm{C}$ and $1.5 \mathrm{Wt} . \%$ $\mathrm{SiC}$ showed superior wear resistance properties with $88.32 \%$ increase in wear resistance compared to monolithic Al. An increase in normal load and speed increases the wear rate of the materials. Frictional coefficients of monolithic $\mathrm{Al}$ and its nanocomposites are in the expected range for light metals in dry sliding conditions. The worn surface of Al alloy exhibited deep long grooves along the direction of sliding. It shows that the ploughing mechanism is predominant in $\mathrm{Al}$ alloy. The worn surface of nanocomposites revealed narrow groves and almost flat surface. This was due to the presence of hard $\mathrm{SiC}$ and $\mathrm{B}_{4} \mathrm{C}$ nanoparticles which restricted the flow of the material under the applied load. Further studies can focus on studying the abrasive wear behaviour of Al-nanocomposites under different abrasive environments.

\section{ACKNOWLEDGEMENTS}

Authors express their sincere thanks to All India Council for Technical Education (AICTE) New Delhi-India, for funding par of this project under Research Promotion Scheme (RPS) on the concept of Ultrasonic Cavitation Based Fabrication of Metal Matrix Nanocomposite Materials (Grant No: 8023/BOR/RID/RPS-92/2009-10/Dated 31.03.2010).

\section{REFERENCES}

[1] Seshan S, Guruprasad A, Prabha M, Sudhakar A. Fibre-reinforced metal matrix composites--a review. Journal of the Indian Institute of Science. 1996;76:1-14.

[2] RamakoteswaraRao V, Ramanaiah N, Srinivasa Rao M, Sarcar MMM, Kartheek G. Optimisation of process parameters for minimum volumetric wear rate on AA7075-TiC metal matrix composite. International Journal of Automotive and Mechanical Engineering. 2016;13:3669-80.

[3] Mohanty S, Routara BC. A review on machining of metal matrix composites using nanoparticle mixed dielectric in electro-discharge machining. International Journal of Automotive and Mechanical Engineering. 2016;13:3518-39.

[4] Sumer Gaaz T, Sulong AB, Akhtar MN, Raza MR. Morphology and tensile properties of thermoplastic polyurethane-halloysite nanotube nanocomposites. International Journal of Automotive and Mechanical Engineering. 2015;12:284456. 
[5] Fatchurrohman N, Sulaiman S, Sapuan SM, Ariffin MKA, Baharuddin BTHT. Analysis of a metal matrix composites automotive component. International Journal of Automotive and Mechanical Engineering. 2015;11:2531-40.

[6] Kök M. Abrasive wear of $\mathrm{Al}_{2} \mathrm{O}_{3}$ particle reinforced 2024 aluminium alloy composites fabricated by vortex method. Composites Part A: Applied Science and Manufacturing. 2006;37:457-64.

[7] Khan MM, Dixit G. Erosive wear response of SiCp reinforced aluminium based metal matrix composite: Effects of test environments. Journal of Mechanical Engineering and Sciences. 2017;14:2401-14.

[8] Maleque MA, Radhi M, Rahman MM. Wear study of Mg-SiCp reinforcement aluminium metal matrix composite. Journal of Mechanical Engineering and Sciences. 2016;10:1758-64.

[9] Rihayat T, Salim S, Agusnar H, Fajri, Zaimahwati. Synthesis of polyurethane/clay nanocomposites based palm oil polyol coating. Journal of Mechanical Engineering and Sciences. 2015;9:1580-6.

[10] Deuis R, Subramanian C, Yellup J. Dry sliding wear of aluminium composites-a review. Composites Science and Technology. 1997;57:415-35.

[11] Das S. Development of aluminium alloy composites for engineering applications. Transactions of Indian Institute of Metals. 2004;57:325-34.

[12] Y1lmaz O, Buytoz S. Abrasive wear of $\mathrm{Al}_{2} \mathrm{O}_{3}$-reinforced aluminium-based MMCs. Composites Science and Technology. 2001;61:2381-92.

[13] Kolawole MY, Aweda JO, Abdulkareem S. Archachatina marginata bio-shells as reinforcement material in metal matrix composites. International Journal of Automotive and Mechanical Engineering. 2017;14:4068-79..

[14] Rao VR, Ramanaiah N, Rao MS, Sarcar M, Kartheek G. Optimisation of process parameters for minimum volumetric wear rate on AA7075-TiC metal matrix composite. International Journal of Automotive and Mechanical Engineering. 2016; 13:3669-80.

[15] Asif Iqbal AKM, Arai Y. Study on low-cycle fatigue behavior of cast hybrid metal matrix composites. International Journal of Automotive and Mechanical Engineering. 2015;11:2504-14.

[16] Adebisi A, Maleque M, Rahman M. Metal matrix composite brake rotor: historical development and product life cycle analysis. International Journal of Automotive and Mechanical Engineering. 2011;4:471-80.

[17] Khan M, Dixit G. Erosive wear response of SiCp reinforced aluminium based metal matrix composite: Effects of test environments. Journal of Mechanical Engineering and Sciences. 2017;11:2401-14.

[18] Poovazhagan L, Kalaichelvan K, Rajadurai A. Preparation of SiC Nanoparticulates Reinforced Aluminum Matrix Nanocomposites by High Intensity Ultrasonic Cavitation Process. Transactions of The Indian Institute of Metals. 2014;67:229-37.

[19] Xiaochun L, Yang Y, Weiss D. Theoretical and experimental study on ultrasonic dispersion of nanoparticles for strengthening cast Aluminum Alloy A356. Metallurgical Science and Tecnology. 2013;26:12-20.

[20] Abedinzadeh R, Safavi S, Karimzadeh F. A comparative study on wear properties of nanostructured $\mathrm{Al}$ and $\mathrm{Al} / \mathrm{Al} 2 \mathrm{O} 3$ nanocomposite prepared by microwaveassisted hot press sintering and conventional hot pressing. Journal of Mechanical Science and Technology. 2015;29:3685-90. 
[21] Mazahery A, Shabani MO. Microstructural and abrasive wear properties of SiC reinforced aluminum-based composite produced by compocasting. Transactions of Nonferrous Metals Society of China. 2013;23:1905-14.

[22] Rohatgi P, Guo R. Mechanism of abrasive wear of Al-Si hypoeutectic alloycontaining 5 vol\% fly ash. Tribology Letters. 1997;3:339-47.

[23] Rohatgi P, Guo R, Huang P, Ray S. Friction and abrasion resistance of cast aluminum alloy-fly ash composites. Metallurgical and Materials Transactions A. 1997;28:245-50.

[24] Kadirgama K, Abou-El-Hossein K, Noor M, Sharma K, Mohammad B. Tool life and wear mechanism when machining Hastelloy C-22HS. Wear. 2011;270:25868.

[25] Arsenault R, Shi N. Dislocation generation due to differences between the coefficients of thermal expansion. Materials Science and Engineering. 1986;81:175-87.

[26] Canakci A, Arslan F. Abrasive wear behaviour of B 4 C particle reinforced Al2024 MMCs. The International Journal of Advanced Manufacturing Technology. 2012;63:785-95.

[27] Poovazhagan L, Kalaichelvan K, Balaji V, Ganesh P, Avudaiappan AK. Development of AA6061/SiCp Metal Matrix Composites by Conventional Stir Casting and Ultrasonic Assisted Casting Routes-A Comparative Study. Advanced Materials Research: Trans Tech Publ; 2014. p. 384-9.

[28] Kumar S, Balasubramanian V. Effect of reinforcement size and volume fraction on the abrasive wear behaviour of AA7075 Al/SiC $p$ P/M composites-A statistical analysis. Tribology International. 2010;43:414-22.

[29] Das S, Das S, Das K. Abrasive wear of zircon sand and alumina reinforced Al$4.5 \mathrm{wt} \% \mathrm{Cu}$ alloy matrix composites-A comparative study. Composites Science and Technology. 2007;67:746-51.

[30] DP M. High Stress abrasive wear behavior of aluminium hard particle composites: Effect of experimental parameters, particle size and volume fraction. Tribology International. 2006;39:470-8.

[31] Das S, Mondal D, Dixit G. Correlation of abrasive wear with microstructure and mechanical properties of pressure die-cast aluminum hard-particle composite. Metallurgical and Materials Transactions A. 2001;32:633-42.

[32] Lim C, Lim S, Gupta M. Wear behaviour of SiC p-reinforced magnesium matrix composites. Wear. 2003;255:629-37.

[33] Elango G, Busuna K, Kayaroganam P. Experimental analysis of the wear behavior of hybrid metal-matrix composites of $1 \mathrm{~m} 25 \mathrm{al}$ with equal volumes of $\mathrm{SiC}+\mathrm{TiO} 2$. Materiali in tehnologije. 2014;48:803-10.

[34] Hasan Z, Pandey R, Sehgal D. Wear Characteristics in Al-SiC Particulate Composites and the Al-Si Piston Alloy. Journal of Minerals \& Materials Characterization \& Engineering. 2011;10:1329-35. 